
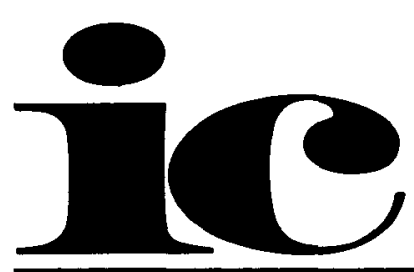

\title{
Pneumococcal Immunization: Strategies for Implementation
}

In an essay written 10 years ago, Lewis Thomas described three very different levels of technology which are used in the management of disease.' The first is a large body of what might be called "nontechnology." This is the supportive care that tides patients through diseases which by and large are not understood. It is an indispensable part of a physician's care, but its cost is high, and getting higher all the time. At the next level is what is best termed "halfway technology." This represents what is done after the fact: making up for disease or postponing death. Chronic dialysis and organ transplantation are examples of halfway technology. This level of technology is, at the same time, highly sophisticated and profoundly primitive. It too is enormously costly. The third type of technology is the kind that is so effective that it often attracts little public notice. Yet, this is the genuinely decisive high technology of modern medicine, and it is exemplified best by modern methods of immunization. The point to be made about this kind of technology is that it is the result of a true understanding of disease mechanisms. When it becomes available, it is inexpensive and easy to deliver. When medicine possesses the outright capacity to prevent human disease, the cost of the technology itself is never a major problem. The price is never as high as the cost of managing the same disease during the earlier stages of nontechnology or halfway technology. However, its effectiveness depends solely upon the intelligence with which it is used.

Reprint requests should be addressed to Dr. David S. Fedson, Department of Medicine, The L'niversity of Chicago, 950 East 59th Street, Chicago, IL 60637.
Pneumococcal vaccine is an example of one of the high technologies of modern medicine. The clinical features ot pneumococcal infections are familiar to all physicians. The biology of the pneumococcus, the epidemiology of pneumococcal disease, host defenses against pneumococcal infection, and the extensive studies on pneumococcal vaccine have been the subjects of detailed reviews. ${ }^{2,3}$ Despite the extraordinary developments in understanding in each of these areas, many questions remain unanswered, and they continue to challenge the imagination and energies of basic and clinical scientists. But the challenges are not solely confined to the domain of biomedical investigation.

Pneumococcal vaccine was licensed for distribution in 1977. Since its release, the Public Health Service has issued initial and revised recommendations for its use, ${ }^{4,5}$ recommendations which have been both cautious and controversial. The Public Health Service has not been the only federal agency concerned with pneumococcal immunization. In 1980, the Congress passed Public Law 96611, which authorized the federal government to pay for the cost of pneumococcal vaccine and its administration to all enrollees in the Medicare program. This legislation, too, was and remains controversial. Nevertheless, the outline of a national policy on pneumococcal immunization has begun to take shape. The extent to which this policy (imperfect though it may be) is being implemented is quite unknown.

Although many conferences have been held which have had as their focus pneumococcal vaccine, much less attention has been given to discussions of strategies for implementing pneumocnccal immunization. With this in 
mind, the Department of Medicine joined with the Committee on Public Policy Studies at the University of Chicago to sponsor a symposium on the subject. It was held on October 22, 1981, and the six articles which appear in this issue of Infection Control are the result of the presentations and discussions. The symposium begins with an update on pneumococcal infections and pneumococcal vaccine. This is followed by a discussion of the implications of cost-effectiveness analysis of pneumococcal vaccination for clinical practice. The important role that hospitals might assume in the prevention of pneumococcal infections is outlined next, followed by reviews of the differing perspectives of Congress and the Advisory Committee on Immunization Practices (ACIP) on pneumococcal immunization policy. The final discussion covers the broad range of issues previously presented, and highlights many practical and important questions regarding the delivery of pneumococcal vaccine.

The readers of Infection Control constitute a community of physicians, scientists, and health care workers primarily concerned with infections in the hospital setting. However, an important part of controlling infections in hospitals is preventing their ever occurring in the community. The prevention of disease and the promotion of health can and should be of as much concern to those who work in hospitals as it is to those who work in other sectors of our health care system. ${ }^{6}$ If this symposium increases awareness of this compelling task, it will have served its purpose.

\section{ACKNOWLEDGMENT}

The authors of all articles in this issue wish to thank Merck, Sharp of Dohme, Division of Merck and Co., Inc., for a generous grant which supported the symposium and publication of the presentations.

\section{REFERENCES}

1. Thomas L: The technology of medicine. N Engl J Med 285:1365$1368,1971$.

2. Quie PG, Giebink GS, Winkelstein JA (eds): The pneumococcus. Rev Infect Dis 3:183-395, 1981.

3. Kass EH (ed): Assessment of the pneumococcal polysaccharide vaccine. Rev Infect $D$ is 3(suppl):S1-197, 1981.

4. Recommendation of the Public Health Service Advisory Committee on Immunization Practices. Pneumococcal polysaccharide vaccine. Morb Mort Weekly Rep 27:25-31, 1978.

5. Recommendation of the Immunization Practices Advisory Commiltee (ACIP). Pneumococral polysaccharide vaccine. Morb Mort Weekly Rep 30:410-419, 1981.

6. Stieger WA: The hospital and the promotion of health. $V$ Engl J Med 281:793-794, 1969.

DAVID S. FEDSON, M.D. ALVIN R. TARLOV, M.D. Department of Medicine The l'niversity of Chicago Chicago, Illinois 